\title{
Role of Gremlin-1 in Cancer
}

\author{
Sin-Aye Park ${ }^{\dagger ;} *$ \\ Department of Biomedical Laboratory Science, College of Medical Sciences, \\ Soonchunhyang University, Asan 31538, Korea
}

Gremlin-1 (GREM1) has been defined as an antagonist of bone morphogenetic proteins (BMPs), particularly during embryonic development and tissue differentiation. However, recent studies have shown that GREM1 has BMPs-dependent or -independent functions in diverse human diseases. GREM1 plays a key role in the process of organ fibrosis, including lungs, kidneys, and so on. The GREM1-induced fibrosis typically promotes the development of other diseases, such as pulmonary hypertension, renal inflammation, and diabetic nephropathy. More recently, considerable evidence has been reported showing that GREM1 is involved in the promotion and/or progression of tumors in vitro and in vivo. It also performs an oncogenic role in the maintenance of cancer stem cells. Although GREM1 is known to function in a variety of diseases, here we focus on the role of GREM1 in cancer, and suggest GREM1 as a potential therapeutic target in certain types of cancer.

Key Words: Gremlin-1, Epithelial-mesenchymal transition, Fibrosis, Cancer, Angiogenesis

\section{INTRODUCTION}

Bone morphogenetic proteins (BMPs) are extracellular proteins that constitute the largest subfamily of the transforming growth factor- $\beta$ (TGF- $\beta$ ) (Bragdon et al., 2011). While BMPs were originally considered to play a role in bone formation, they have been known to perform diverse actions in biological processes including organogenesis and tissue differentiation. BMPs bind to BMP receptors, which are serine/threonine kinase receptors at the cell surface, to induce certain signaling pathways (Wang et al., 2014).

Importantly, the BMP-induced signaling pathways can be inhibited by a family of BMP antagonists: these bind directly to BMP ligands, then prevent interaction with the BMP receptors and their ligands (Canalis et al., 2003; Ali and Brazil, 2014). Gremlin-1 (GREM1), a BMP antagonist, was first identified from its antagonism of BMPs during embryonic development (Canalis et al., 2003). Transgenic mice overexpressing Greml exhibited bone fractures and reduced bone mineral density compared to controls (Gazzerro et al., 2005), whereas Greml-conditional null mice displayed increased bone formation and mass (Gazzerro et al., 2007). GREM1 is also important for organ development. The targeted deletion or overexpression of GREM1 has been shown to cause lung (Cahill et al., 2012) or kidney (Church et al., 2017) abnormalities. In addition to its role in organogenesis, numerous studies have shown that GREM1 is a key molecule in the induction of tissue fibrosis (Myllarniemi et al., 2008; Heron et al., 2011).

Received: October 22, 2018 / Accepted: December 4, 2018

*Professor

† Corresponding author: Sin-Aye Park. Department of Biomedical Laboratory Science, College of Medical Sciences, Soonchunhyang University, Asan 31538, Korea.

Tel: +82-41-530-4990, Fax: +82-41-530-3085, e-mail: sappark@sch.ac.kr

(C) The Korean Society for Biomedical Laboratory Sciences. All rights reserved.

(c) This is an Open Access article distributed under the terms of the Creative Commons Attribution Non-Commercial License (http://creativecommons.org/licenses/by-nc/3.0/) which permits unrestricted non-commercial use, distribution, and reproduction in any medium, provided the original work is properly cited. 


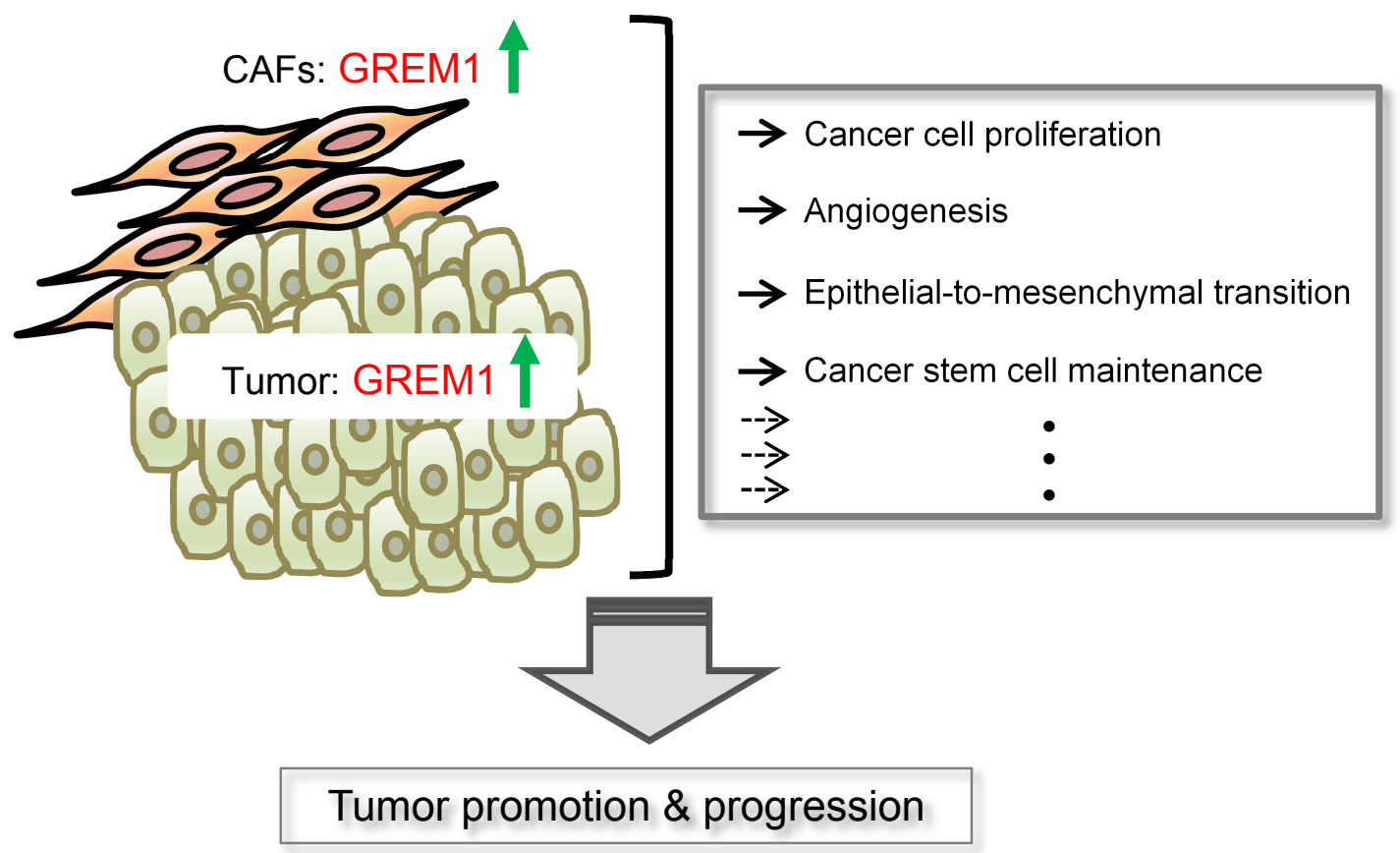

Fig. 1. The role of GREM1 in cancer. The level of GREM1 is increased in several types of tumors and/or their surrounded stroma, particularly cancer-associated fibroblasts (CAFs). The overexpression of GREM1 in tumors and/or CAFs enhances the proliferation, angiogenesis, and epithelial-to-mesenchymal transition of cancer cells. In addition, it plays a role in cancer stem cell maintenance. Overall, GREM1 may eventually contribute to tumor promotion and progression.

Currently, GREM1 is known to be as a novel oncogenic or pro-angiogenic factor in cancer. The level of GREM1 has been shown to be overexpressed in multiple tumors and their stroma (Namkoong et al., 2006; Sneddon et al., 2006). GREM1 regulated the cancer cell growth (Kim et al., 2012; Wang et al., 2012) and cancer stem cell maintenance (Yan et al., 2014; Sato et al., 2016). In addition, GREM1 has been reported to mimic the effects of vascular endothelial growth factor (VEGF) on the VEGF receptor 2 (VEGFR2) in endothelial cells (Stabile et al., 2007), and to induce the epithelialto-mesenchymal transition (EMT) in various cancer cells (Guan et al., 2017; Yin et al., 2017). Although there may be more roles of GREM1 in cancer, in this review, we particularly summarize some of the prominent functions of GREM1 (Fig. 1).

\section{Expression of GREM1 in tumors}

Numerous studies have reported that the level of GREM1 is overexpressed in tumors compared to in surrounding normal tissues; this phenomenon has been observed in car- cinomas of the colon (Galamb et al., 2012; Pelli et al., 2016; Li et al., 2017), lung (Mulvihill et al., 2012), gastric (Yamasaki et al., 2018), liver (Guimei et al., 2012), breast (Schuetz et al., 2006), and so on. The levels of mRNA and protein were both shown to be increased in the majority of human malignant mesothelioma tissues compared to control subjects (Wang et al., 2012). More recently, bioinformatic tools have been used to analyze the microRNAs and their target genes for the diagnosis of esophageal cancer, and GREM1 has been identified as one of those target genes. Subsequently, the expression of GREM1 was shown to be significantly increased in esophageal tumors compared to normal tissues (Cai et al., 2018). A common GREM1 polymorphism, rs16969681, has also been associated with colorectal cancer susceptibility and the higher Greml mRNA levels increased the intestinal tumor burden in Apc (Min) mice (Lewis et al., 2014). In this context, a low-frequency variant rs12915554 in the 3' untranslated regions of GREM1 was also reported to be associated with colorectal cancer risk (Li et al., 2017). 
Interestingly, GREM1 expression has been noticed not only in cancer cells but also in their surrounding stromal cells or cancer-associated fibroblasts. For example, GREM1 was widely overexpressed in the stroma of basal cell carcinoma of the skin, but not in the corresponding normal tissue counterparts (Sneddon et al., 2006). GREM1 expression was also particularly localized to activated myofibroblasts at the tumoral-stromal interface of basal cell carcinomas or scar tissues (Kim et al., 2017). In addition, GREM1-expressing fibroblasts are frequently observed in colorectal cancers, suggesting stromal GREM1 as a potential biomarker and possible candidate for the treatment of colorectal cancers (Jang et al., 2017).

\section{GREM1 and tumor growth}

Increasing evidence suggests that high GREM1 expression affects the biological properties of cancer cells both in vitro and in vivo. Aberrant epithelial GREM1 expression has been shown to initiate colonic tumorigenesis in a synergistic fashion with Wnt signaling. Specifically, Greml knockout markedly reduced Wnt-driven tumor progression in vivo (Davis et al., 2015). GREM1 knockdown using shRNA has also resulted in the inhibition of malignant mesothelioma cells (Wang et al., 2012). Likewise, treatment of recombinant GREM1 protein promoted the proliferation of basal cell carcinoma cells (Sneddon et al., 2006) and overexpression of GREM1 increased the growth of lung fibroblasts and epithelial cells (Mulvihill et al., 2012). Interestingly, GREM1 has been shown to directly interact with various types of cancer cells in a BMP-independent manner and it promoted proliferation, migration, and invasion of cancer cells (Kim et al., 2012).

Growing evidence has implicated that cancer stem cells play critical roles in tumor growth, recurrence, metastasis, and drug resistance (Chang, 2016). It has been shown that GREM1 promotes cancer stem cell maintenance, particularly in glioma and cervical cancer (Yan et al., 2014; Sato et al., 2016). The overexpression of GREM1 in non-glioma cancer stem cells decreased their endogenous BMP signaling to promote stem-like features and further increased the growth and tumor formation (Yan et al., 2014). In CaSki cervical cancer cells, the incubation with GREM1 has also been shown to enhance the level of Nanog, one of the undifferentiated cell markers, and to increase their sphere-forming ability, thus maintaining their cancer stem cell-like properties (Sato et al., 2016).

\section{GREM1 and angiogenesis}

Angiogenesis is an important process that promotes the aggressiveness of tumors. It has been reported that treatment of recombinant GREM1 stimulates the migration and invasion of endothelial cells. GREM1 has also been shown to be highly expressed in the endothelial cells of lung tumor vasculature, as compared to non-neoplastic lung (Stabile et al., 2007). The expression of GREM1 was correlated with microvessel density, suggesting its pro-angiogenic role in pancreatic neuroendocrine tumors (Chen et al., 2013). Moreover, GREM1 knockdown has been shown to reduce the proliferation, migration, and invasion of synoviocytes (Han et al., 2016). GREM1 promoted mesothelioma cell sprouting and invasion in vitro and it was overexpressed in tumors with a tendency to drive metastasis (Yin et al., 2017). Furthermore, GREM1 was overexpressed in desmoplastic invasion fronts in colorectal cancer (Karagiannis et al., 2014). Enrichment map profiling of the cancer invasion front suggested that GREM1 may trigger the motility of colorectal cancer cells (Karagiannis et al., 2013).

Remarkably, angiogenic VEGFR2 was bound by GREM1 in a BMP-independent manner, which activated VEGFR2dependent angiogenic responses in vitro and in vivo (Mitola et al., 2010). Another study showed that the administration of recombinant GREM1 to murine kidneys induced sustained activation of VEGFR2 signaling (Lavoz et al., 2015). These findings suggest that the GREM1-VEGFR2 axis may be a promising target for multiple diseases including cancer (Erdmann et al., 2015).

\section{GREM1 and EMT}

The EMT is a phenomenon in which epithelial cells loosen their cell-cell adhesion structures and become isolated and mobile (Savagner, 2010). EMT also plays a role in the genesis of fibroblasts during organ fibrosis or the transition of normal cells to transformed cell phenotypes during cancer progression (Kalluri and Neilson, 2003). It is well known that GREM1 
is a key molecule in promoting pulmonary (Myllarniemi et al., 2008; Farkas et al., 2011) or renal fibrosis (Church et al., 2017). Importantly, the process of EMT is critically involved in GREM1-induced organ fibrosis (Allison, 2015).

In tubular epithelial cells, treatment of GREM1 has been shown to activate the TGF- $\beta 1 /$ Smad signaling pathway which is a critical mechanism in the process of EMT or fibrosis (Rodrigues-Diez et al., 2014). Stimulation with recombinant GREM1 augmented EMT changes with the loss of epithelial markers and induction of mesenchymal markers in murine fibroblasts (Rodrigues-Diez et al., 2012) and in retinal pigment epithelial cells (Lee et al., 2007). According to another study, GREM1 also induced EMT by cadherin switching (loss of E-cadherin and upregulation of N-cadherin) and the overexpression of Snail, one of the major transcription factors involved in EMT regulation, in colon cancer cells (Karagiannis et al., 2015). The interaction between GREM1 and fibrillin microfibrils regulated malignant mesothelioma cell survival through the activation of another transcription factor Slug as well as mesenchymal proteins (Tamminen et al., 2013). GREM1 has been shown to promote carcinogenesis of glioma by regulating EMT. The knockdown of GREM1 abolished the TGF- $\beta 1$-mediated activation of the Smad pathway, followed by the reduction of viability, migration, and invasion in glioma cells (Guan et al., 2017). More recently, the expression of GREM1 in mesenchymal stromal cells promoted EMT in human esophageal squamous cell carcinoma with an alteration in the expression levels of epithelial and mesenchymal markers (Hong et al., 2018).

\section{CONCLUSION}

GREM1 is well known to be involved in the fibrosis of various organs including lungs (Myllarniemi et al., 2008) and kidneys (Church et al., 2017). In fact, GREM1 has been revealed to be one of the novel markers of liver fibrogenesis through the serial analysis of gene expression (Boers et al., 2006). In addition, GREM1 has been defined as a novel pro-fibrogenic factor in chronic pancreatitis (Staloch et al., 2015). In addition to organ fibrosis, increasing evidence has suggested that GREM1 plays an oncogenic role in multistep carcinogenesis. The level of GREM1 is increased in various types of cancer cells both in vitro and in vivo (Schuetz et al., 2006; Mulvihill et al., 2012). Interestingly, GREM1 induces the proliferation, migration, and invasion of cancer cells (Kim et al., 2012; Yin et al., 2017). Apart from its role as an antagonist of BMP, GREM1 plays unique roles in a more complex pathological environment. GREM1 is widely expressed in cancer-associated stromal cells (Sneddon et al., 2006) and overexpressed in the cancer-associated myofibroblasts of basal cell carcinomas (Kim et al., 2017). These results also indicate that GREM1 can affect the promotion and progression of a tumor, not only in the tumor itself but also in the environment surrounding the tumor.

Although the involvement of GREM1 in metastasis has not been well-defined, GREM1 is one of the key regulators that can trigger the motility of cancer cells at the cancer invasion front (Karagiannis et al., 2013). GREM1-induced EMT may particularly affect the metastasis of cancer cells. BMP2/7 heterodimer has been shown to strongly inhibit the formation of bone metastasis, suggesting the role of BMP antagonists such as Coco, GREM1, etc., as an oncogenic driver of metastasis (Buijs et al., 2012). Moreover, Coco was reported to reactivate breast cancer cells at lung metastatic sites in vivo (Gao et al., 2012). Although the role of GREM1 in carcinogenesis has not yet been extensively investigated, we suggest here that GREM1 may be critically involved in tumor promotion and progression.

Previously, treatment with anti-GREM1 monoclonal antibody was shown to ameliorate chronic hypoxia/SU5416induced pulmonary arterial hypertension in mice (Ciuclan et al., 2013). It has also been reported that microRNA-27b directly targeted GREM1 by binding to its 3'-UTR, reducing the GREM1 mRNA level in pulmonary cells (Graham et al., 2014). GREM1 may be a potential therapeutic target in a number of diseases including cancer, but there are still few reports of effective inhibitors for GREM1. In addition, future studies are necessary to determine the mechanism by which GREM1 expression is regulated as well as the mechanism by which it regulates other molecules.

\section{ACKNOWLEDGMENT}

This work was supported by the Soonchunhyang University Research Fund (No. 20180405) and by Basic Science 
Research Program through the National Research Foundation of Korea (NRF) funded by the Ministry of Education (2017R1A6A3A11032154).

\section{CONFLICT OF INTEREST}

No potential conflict of interest relevant to this article was reported.

\section{REFERENCES}

Ali IH, Brazil DP. Bone morphogenetic proteins and their antagonists: Current and emerging clinical uses. Br J Pharmacol. 2014. 171: 3620-3632.

Allison SJ. Fibrosis: Targeting emt to reverse renal fibrosis. Nat Rev Nephrol. 2015. 11: 565

Boers W, Aarrass S, Linthorst C, Pinzani M, Elferink RO, Bosma P. Transcriptional profiling reveals novel markers of liver fibrogenesis: Gremlin and insulin-like growth factor-binding proteins. J Biol Chem. 2006. 281: 16289-16295.

Bragdon B, Moseychuk O, Saldanha S, King D, Julian J, Nohe A. Bone morphogenetic proteins: A critical review. Cell Signal. 2011. 23: 609-620.

Buijs JT, van der Horst G, van den Hoogen C, Cheung H, de Rooij B, Kroon J, Petersen M, van Overveld PG, Pelger RC, van der Pluijm G. The bmp2/7 heterodimer inhibits the human breast cancer stem cell subpopulation and bone metastases formation. Oncogene. 2012. 31: 2164-2174.

Cahill E, Costello CM, Rowan SC, Harkin S, Howell K, Leonard MO, Southwood M, Cummins EP, Fitzpatrick SF, Taylor CT, Morrell NW, Martin F, McLoughlin P. Gremlin plays a key role in the pathogenesis of pulmonary hypertension. Circulation. 2012. 125: 920-930.

Cai X, Yang X, Jin C, Li L, Cui Q, Guo Y, Dong Y, Yang X, Guo L, Zhang M. Identification and verification of differentially expressed micrornas and their target genes for the diagnosis of esophageal cancer. Oncol Lett. 2018. 16: 3642-3650.

Canalis E, Economides AN, Gazzerro E. Bone morphogenetic proteins, their antagonists, and the skeleton. Endocr Rev. 2003. 24: $218-235$.

Chang JC. Cancer stem cells: Role in tumor growth, recurrence, metastasis, and treatment resistance. Medicine (Baltimore). 2016. 95: S20-25.

Chen MH, Yeh YC, Shyr YM, Jan YH, Chao Y, Li CP, Wang SE, Tzeng CH, Chang PM, Liu CY, Chen MH, Hsiao M, Huang
CY. Expression of gremlin 1 correlates with increased angiogenesis and progression-free survival in patients with pancreatic neuroendocrine tumors. J Gastroenterol. 2013. 48: 101-108.

Church RH, Ali I, Tate M, Lavin D, Krishnakumar A, Kok HM, Hombrebueno JR, Dunne PD, Bingham V, Goldschmeding R, Martin F, Brazil DP. Gremlin1 plays a key role in kidney development and renal fibrosis. Am J Physiol Renal Physiol. 2017. 312: F1141-F1157.

Ciuclan L, Sheppard K, Dong L, Sutton D, Duggan N, Hussey M, Simmons J, Morrell NW, Jarai G, Edwards M, Dubois G, Thomas M, Van Heeke G, England K. Treatment with antigremlin 1 antibody ameliorates chronic hypoxia/su5416-induced pulmonary arterial hypertension in mice. Am J Pathol. 2013. 183: 1461-1473.

Davis H, Irshad S, Bansal M, Rafferty H, Boitsova T, Bardella C, Jaeger E, Lewis A, Freeman-Mills L, Giner FC, RodenasCuadrado P, Mallappa S, Clark S, Thomas H, Jeffery R, Poulsom R, Rodriguez-Justo M, Novelli M, Chetty R, Silver A, et al. Aberrant epithelial grem1 expression initiates colonic tumorigenesis from cells outside the stem cell niche. Nat Med. 2015. 21: 62-70.

Erdmann R, Ozden C, Weidmann J, Schultze A. Targeting the gremlin-vegfr2 axis - a promising strategy for multiple diseases? J Pathol. 2015. 236: 403-406.

Farkas L, Farkas D, Gauldie J, Warburton D, Shi W, Kolb M. Transient overexpression of gremlin results in epithelial activation and reversible fibrosis in rat lungs. Am J Respir Cell Mol Biol. 2011. 44: 870-878.

Galamb O, Wichmann B, Sipos F, Spisak S, Krenacs T, Toth K, Leiszter K, Kalmar A, Tulassay Z, Molnar B. Dysplasiacarcinoma transition specific transcripts in colonic biopsy samples. PLoS One. 2012. 7: e48547.

Gao H, Chakraborty G, Lee-Lim AP, Mo Q, Decker M, Vonica A, Shen R, Brogi E, Brivanlou AH, Giancotti FG. The bmp inhibitor coco reactivates breast cancer cells at lung metastatic sites. Cell. 2012. 150: 764-779.

Gazzerro E, Pereira RC, Jorgetti V, Olson S, Economides AN, Canalis E. Skeletal overexpression of gremlin impairs bone formation and causes osteopenia. Endocrinology. 2005. 146: 655-665.

Gazzerro E, Smerdel-Ramoya A, Zanotti S, Stadmeyer L, Durant D, Economides AN, Canalis E. Conditional deletion of gremlin causes a transient increase in bone formation and bone mass. J Biol Chem. 2007. 282: 31549-31557.

Graham JR, Williams CM, Yang Z. Microrna-27b targets gremlin 
1 to modulate fibrotic responses in pulmonary cells. J Cell Biochem. 2014. 115: 1539-1548.

Guan Y, Cheng W, Zou C, Wang T, Cao Z. Gremlin1 promotes carcinogenesis of glioma in vitro. Clin Exp Pharmacol Physiol. 2017. 44: 244-256.

Guimei M, Baddour N, Elkaffash D, Abdou L, Taher Y. Gremlin in the pathogenesis of hepatocellular carcinoma complicating chronic hepatitis c: An immunohistochemical and pcr study of human liver biopsies. BMC Res Notes. 2012. 5: 390.

Han EJ, Yoo SA, Kim GM, Hwang D, Cho CS, You S, Kim WU. Grem1 is a key regulator of synoviocyte hyperplasia and invasiveness. J Rheumatol. 2016. 43: 474-485.

Heron M, van Moorsel CH, Grutters JC, Huizinga TW, van der Helm-van Mil AH, Nagtegaal MM, Ruven HJ, van den Bosch JM. Genetic variation in grem1 is a risk factor for fibrosis in pulmonary sarcoidosis. Tissue Antigens. 2011. 77: 112-117.

Hong D, Liu T, Huang W, Liao Y, Wang L, Zhang Z, Chen H, Zhang $\mathrm{X}$, Xiang Q. Gremlin1 delivered by mesenchymal stromal cells promoted epithelial-mesenchymal transition in human esophageal squamous cell carcinoma. Cell Physiol Biochem. 2018. 47: 1785-1799.

Jang BG, Kim HS, Chang WY, Bae JM, Oh HJ, Wen X, Jeong S, Cho NY, Kim WH, Kang GH. Prognostic significance of stromal grem1 expression in colorectal cancer. Hum Pathol. 2017. 62: 56-65.

Kalluri R, Neilson EG. Epithelial-mesenchymal transition and its implications for fibrosis. J Clin Invest. 2003. 112: 1776-1784.

Karagiannis GS, Berk A, Dimitromanolakis A, Diamandis EP. Enrichment map profiling of the cancer invasion front suggests regulation of colorectal cancer progression by the bone morphogenetic protein antagonist, gremlin-1. Mol Oncol. 2013. 7: 826-839.

Karagiannis GS, Musrap N, Saraon P, Treacy A, Schaeffer DF, Kirsch R, Riddell RH, Diamandis EP. Bone morphogenetic pro tein antagonist gremlin-1 regulates colon cancer progression. Biol Chem. 2015. 396: 163-183.

Karagiannis GS, Treacy A, Messenger D, Grin A, Kirsch R, Riddell RH, Diamandis EP. Expression patterns of bone morphogenetic protein antagonists in colorectal cancer desmoplastic invasion fronts. Mol Oncol. 2014. 8: 1240-1252.

Kim HS, Shin MS, Cheon MS, Kim JW, Lee C, Kim WH, Kim YS, Jang BG. Grem1 is expressed in the cancer-associated myofibroblasts of basal cell carcinomas. PLoS One. 2017. 12: e0174565.

Kim M, Yoon S, Lee S, Ha SA, Kim HK, Kim JW, Chung J.
Gremlin-1 induces bmp-independent tumor cell proliferation, migration, and invasion. PLoS One. 2012. 7: e35100.

Lavoz C, Alique M, Rodrigues-Diez R, Pato J, Keri G, Mezzano S, Egido J, Ruiz-Ortega M. Gremlin regulates renal inflammation via the vascular endothelial growth factor receptor 2 pathway. J Pathol. 2015. 236: 407-420.

Lee H, O'Meara SJ, O'Brien C, Kane R. The role of gremlin, a bmp antagonist, and epithelial-to-mesenchymal transition in proliferative vitreoretinopathy. Invest Ophthalmol Vis Sci. 2007. 48: 4291-4299.

Lewis A, Freeman-Mills L, de la Calle-Mustienes E, GiraldezPerez RM, Davis H, Jaeger E, Becker M, Hubner NC, Nguyen LN, Zeron-Medina J, Bond G, Stunnenberg HG, Carvajal JJ, Gomez-Skarmeta JL, Leedham S, Tomlinson I. A polymorphic enhancer near grem1 influences bowel cancer risk through differential cdx2 and tcf712 binding. Cell Rep. 2014. 8: 983 -990 .

Li J, Liu H, Zou L, Ke J, Zhang Y, Zhu Y, Yang Y, Gong Y, Tian J, Zou D, Peng X, Gong J, Zhong R, Huang K, Chang J, Miao $\mathrm{X}$. A functional variant in grem1 confers risk for colorectal cancer by disrupting a hsa-mir-185-3p binding site. Oncotarget. 2017. 8: 61318-61326.

Mitola S, Ravelli C, Moroni E, Salvi V, Leali D, Ballmer-Hofer K, Zammataro L, Presta M. Gremlin is a novel agonist of the major proangiogenic receptor vegfr2. Blood. 2010. 116: 3677 -3680 .

Mulvihill MS, Kwon YW, Lee S, Fang LT, Choi H, Ray R, Kang HC, Mao JH, Jablons D, Kim IJ. Gremlin is overexpressed in lung adenocarcinoma and increases cell growth and proliferation in normal lung cells. PLoS One. 2012. 7: e42264.

Myllarniemi M, Lindholm P, Ryynanen MJ, Kliment CR, Salmenkivi K, Keski-Oja J, Kinnula VL, Oury TD, Koli K. Gremlin-mediated decrease in bone morphogenetic protein signaling promotes pulmonary fibrosis. Am J Respir Crit Care Med. 2008. 177: 321-329.

Namkoong H, Shin SM, Kim HK, Ha SA, Cho GW, Hur SY, Kim TE, Kim JW. The bone morphogenetic protein antagonist gremlin 1 is overexpressed in human cancers and interacts with ywhah protein. BMC Cancer. 2006. 6: 74.

Pelli A, Vayrynen JP, Klintrup K, Makela J, Makinen MJ, Tuomisto A, Karttunen TJ. Gremlin1 expression associates with serrated pathway and favourable prognosis in colorectal cancer. Histopathology. 2016. 69: 831-838.

Rodrigues-Diez R, Lavoz C, Carvajal G, Rayego-Mateos S, Rodrigues Diez RR, Ortiz A, Egido J, Mezzano S, Ruiz-Ortega 
M. Gremlin is a downstream profibrotic mediator of transforming growth factor-beta in cultured renal cells. Nephron Exp Nephrol. 2012. 122: 62-74.

Rodrigues-Diez R, Rodrigues-Diez RR, Lavoz C, Carvajal G, Droguett A, Garcia-Redondo AB, Rodriguez I, Ortiz A, Egido J, Mezzano S, Ruiz-Ortega M. Gremlin activates the smad pathway linked to epithelial mesenchymal transdifferentiation in cultured tubular epithelial cells. Biomed Res Int. 2014. 2014: 802841.

Sato M, Kawana K, Fujimoto A, Yoshida M, Nakamura H, Nishida H, Inoue T, Taguchi A, Takahashi J, Adachi K, Nagasaka K, Matsumoto Y, Wada-Hiraike O, Oda K, Osuga Y, Fujii T. Clinical significance of gremlin 1 in cervical cancer and its effects on cancer stem cell maintenance. Oncol Rep. 2016. 35: 391-397.

Savagner P. The epithelial-mesenchymal transition (emt) phenomenon. Ann Oncol. 2010. 21 Suppl 7: vii89-92.

Schuetz CS, Bonin M, Clare SE, Nieselt K, Sotlar K, Walter M, Fehm T, Solomayer E, Riess O, Wallwiener D, Kurek R, Neubauer HJ. Progression-specific genes identified by expression profiling of matched ductal carcinomas in situ and invasive breast tumors, combining laser capture microdissection and oligonucleotide microarray analysis. Cancer Res. 2006. 66: 5278-5286.

Sneddon JB, Zhen HH, Montgomery K, van de Rijn M, Tward AD, West R, Gladstone H, Chang HY, Morganroth GS, Oro AE, Brown PO. Bone morphogenetic protein antagonist gremlin 1 is widely expressed by cancer-associated stromal cells and can promote tumor cell proliferation. Proc Natl Acad Sci U S A. 2006. 103: 14842-14847.

Stabile H, Mitola S, Moroni E, Belleri M, Nicoli S, Coltrini D, Peri F, Pessi A, Orsatti L, Talamo F, Castronovo V, Waltregny D, Cotelli F, Ribatti D, Presta M. Bone morphogenic protein antagonist drm/gremlin is a novel proangiogenic factor. Blood. 2007. 109: 1834-1840.

Staloch D, Gao X, Liu K, Xu M, Feng X, Aronson JF, Falzon M,
Greeley GH, Rastellini C, Chao C, Hellmich MR, Cao Y, Ko TC. Gremlin is a key pro-fibrogenic factor in chronic pancreatitis. J Mol Med (Berl). 2015. 93: 1085-1093.

Tamminen JA, Parviainen V, Ronty M, Wohl AP, Murray L, Joenvaara S, Varjosalo M, Lepparanta O, Ritvos O, Sengle G, Renkonen R, Myllarniemi M, Koli K. Gremlin-1 associates with fibrillin microfibrils in vivo and regulates mesothelioma cell survival through transcription factor slug. Oncogenesis. 2013. 2: e66

Wang DJ, Zhi XY, Zhang SC, Jiang M, Liu P, Han XP, Li J, Chen $\mathrm{Z}$, Wang CL. The bone morphogenetic protein antagonist gremlin is overexpressed in human malignant mesothelioma. Oncol Rep. 2012. 27: 58-64.

Wang RN, Green J, Wang Z, Deng Y, Qiao M, Peabody M, Zhang Q, Ye J, Yan Z, Denduluri S, Idowu O, Li M, Shen C, Hu A, Haydon RC, Kang R, Mok J, Lee MJ, Luu HL, Shi LL. Bone morphogenetic protein (bmp) signaling in development and human diseases. Genes Dis. 2014. 1: 87-105.

Yamasaki Y, Ishigami S, Arigami T, Kita Y, Uchikado Y, Kurahara H, Kijima Y, Maemura K, Natsugoe S. Expression of gremlin1 in gastric cancer and its clinical significance. Med Oncol. 2018. 35: 30 .

Yan K, Wu Q, Yan DH, Lee CH, Rahim N, Tritschler I, DeVecchio J, Kalady MF, Hjelmeland AB, Rich JN. Glioma cancer stem cells secrete gremlin 1 to promote their maintenance within the tumor hierarchy. Genes Dev. 2014. 28: 1085-1100.

Yin M, Tissari M, Tamminen J, Ylivinkka I, Ronty M, von Nandelstadh P, Lehti K, Hyytiainen M, Myllarniemi M, Koli K. Gremlin-1 is a key regulator of the invasive cell phenotype in mesothelioma. Oncotarget. 2017. 8: 98280-98297.

https://doi.org/10.15616/BSL.2018.24.4.285

Cite this article as: Park SA. Role of Gremlin-1 in Cancer. Biomedical Science Letters. 2018. 24: 285-291. 